\section{Projeto: Documentação e Transmissão dos Saberes Tradicionais dos Asurini do Xingu ${ }^{1}$}

\author{
Regina Polo Müller ${ }^{2}$
}

\section{Objetivos gerais:}

1. Contribuir para as condições de transmissão, produção e reprodução de bens culturais imateriais dos Asuriní do Xingu;

2. Contribuir para a preservação da diversidade étnica e cultural do país e para a disseminação de informações sobre o patrimônio cultural brasileiro a diversos segmentos da sociedade.

\section{Objetivos específicos:}

1. Tratar, digitalizar e organizar o acervo existente de fitas K.7, VHS, Betacam, fitas de rolo, fotografias e, outros sobre patrimônio imaterial Asuriní;

2. Disponibilizar acervo de cultura imaterial para a comunidade Asuriní como forma de incrementar os usos e práticas dos conhecimentos tradicionais;

3. Fortalecer a escola indígena como espaço para o incremento dos conhecimentos tradicionais e para a transmissão de tais conhecimentos para as novas gerações;

4. Promover a devolução do conhecimento acadêmico produzido sobre a cultura imaterial Asuriní à comunidade indígena;

1 Trabalho apresentado na Mesa 5: Museus, identidades e patrimônio cultural.

2 Antropóloga. Professora associada do Instituto de Artes. Universidade de Campinas/UNICAMP.
5. Articular pesquisas em andamento sobre cultura imaterial Asuriní ao trabalho com material de acervo existente;

6. Disponibilizar acervo de cultura imaterial para Instituições Públicas de Ensino Superior, como forma de incentivar pesquisas acadêmicas e garantir à comunidade acadêmica o acesso à cultura imaterial Asuriní;

7. Sensibilizar a população da região (Município de Altamira) para a realidade Asuriní e para importância do patrimônio cultural imaterial na formação da sociedade brasileira.

\section{Metodologia:}

1 etapa: Digitalização do material áudiovisual

Nessa etapa, o material áudio-visual sobre a cultura Asuriní ( 75 horas de vídeo em VHS, Betacam e Super 8, 35 horas de áudio em fita $\mathrm{K} 7,16$ horas de áudio em rolo e 113 desenhos de grafismos Asuriní, 437 slides e 275 negativos, contatos e ampliações $\mathrm{PB}$ ) foi digitalizado. Para tanto, foi necessária a contratação dos serviços de estúdio e de digitalização de imagem, que foram monitorados por bolsistas do projeto e pelo responsável técnico. Foram fotografados em suporte digital 300 objetos da cultura material Asuriní que se encontram em acervo pessoal da antropóloga Regina Polo Muller.

$2^{a}$ etapa: Organização e catalogação do material áudio-visual

As atividades dessa etapa foram realizadas em conjunto por pesquisadores, bolsistas (que também são pesquisadores) e índios Asuriní. Para organização e catalogação de material em vídeo sobre rituais xamanísticos, foi 
necessário o trabalho de identificação dos objetos, etapas e papéis rituais, tradução dos cantos e narrativas míticas, dentre outras. Regina P. Muller, que há cerca de trinta anos se dedica ao estudo das manifestações estéticas do grupo indígena, especialmente a dança na performance ritual, realizou a catalogação e organização do material a partir de sessões de vídeo com toda a equipe.

O trabalho com material em áudio seguiu as atividades descritas acima, já que também consiste em registro dos rituais xamanísticos, mas em suporte de áudio.

O trabalho com as fotografias dos objetos de cultura material foi realizado por índioartesão dos objetos tradicionais, bolsistas e pela pesquisadora Fabíola Andréa Silva que vem coordenando trabalho de análise e registro de acervos etnográficos da cultura material Asuriní, com apoio da FAPESP. Os objetos foram catalogados tendo em vista os materiais necessários, os processos de produção empregados, seus usos e o modo de transmissão desses conhecimentos às gerações mais novas.

\section{$3^{a}$ etapa: Elaboração dos produtos finais}

CD-Rom: elaboração de um CD-Rom com amostra significativa do material áudiovisual Asuriní, espécie de inventário da cultura Asuriní, para ser usado por educadores, pesquisadores e pelos próprios índios numa etapa posterior.

Elaboração de 20 Kits do material editado, cada qual contendo: $1 \mathrm{Cd}-\mathrm{Rom} ;-5 \mathrm{~h}$ de vídeo em DVD; 6 h de áudio em CD; 1 Catálogo impresso com material constante do kit e informações sobre o acervo e o projeto.

Site: confecção de site a partir da estrutura do CD-Rom, com a mesma função de ser um inventário da cultura Asuriní, mas com a vantagem de possuir maior capacidade de armazenar o material digitalizado, a possibilidade de ser atualizado a todo momento e de ser acessível ao público interessado em geral.

$4^{a}$ etapa: Fechamento do projeto e distribuição do material editado

A distribuição do material editado vem sendo realizada pela UNICAMP (Funcamp). Os Cd- Rom foram distribuídos para 20 escolas pú- blicas do Município de Altamira, pela Secretaria de Educação do Município. Membros da equipe do projeto (Regina P. Muller e Alice Villela) ministraram curso para os professores da escola indígena Asuriní bem como para os demais professores da rede pública, no qual foram abordados aspectos da cultura imaterial Asuriní e formas de uso do Cd-Rom nas atividades didáticas de ensino. $\mathrm{O}$ curso foi realizado em Altamira durante dois dias e teve o apoio da Secretaria Municipal de Educação da cidade.

\section{Público alvo:}

Comunidade indígena Asuriní - Altamira/PA. Em particular, professores e alunos da escola indígena.

Comunidade acadêmica de Instituições de Ensino Superior nas quais o acervo de cultura imaterial editado foi disponibilizado: Universidade Estadual de Campinas e Universidade de São Paulo. O material também foi disponibilizado ao Museu Paraense Emílio Goeldi.

Professores e alunos da rede pública de ensino do Munícipio de Altamira. As escolas receberam o CD-Rom com inventário do material áudio-visual Asuriní. e curso no qual foram abordados aspectos gerais da cultura Asuriní e as formas de uso do CD-Rom nas atividades didáticas de ensino.

\section{Avaliação de impacto local, regional e nacional:}

Espera-se que a comunidade Asuriní tenha acesso ao rico material áudio-visual produzido por pesquisadores que, desde a década de 70 , se dedicam à pesquisa dos saberes tradicionais do grupo (cantos e danças dos rituais, mitos e conhecimentos envolvidos na confecção de 
objetos da cultura material, dentre outros). A devolução desse material deve incrementar a produção da cultura imaterial e material indígena, já que terão acesso a detalhes formais de cantos, processos rituais, técnicas e conhecimentos que podem ter se perdido no tempo ou cujos detentores necessitam de estímulo para reproduzi-los e transmiti-los. Além disso, o retorno do material aos Asuriní e o trabalho a médio prazo dentro da escola indígena, através da utilização de material visual e sonoro incorporado ao material didático, pode estimular o interesse de crianças e jovens pelo aprendizado dos saberes tradicionais, fortalecendo a identidade Asuriní num contexto de relações interétnicas.

Disponibilizando o Cd-Rom aos professores da rede pública de ensino do Município de Altamira, espera-se contribuir para a melhor inclusão e tratamento da temática indígena na sala de aula.

Ao disponibilizar cópia do material editado para instituições de Ensino Superior, pretende-se estimular a produção de conhecimento e divulgar os saberes tradicionais Asuriní para a comunidade acadêmica de um modo geral.

\section{Instituições envolvidas:}

O projeto foi desenvolvido através do auxílio financeiro do MINC/IPHAN (Edital PNPI MINC/IPHAN n ${ }^{\circ} 001 / 2005$ ) e de parcerias estabelecidas entre FUNCAMP, Instituto de Artes/ UNICAMP, FUNAI- Fundação Nacional do Índio, MAE- Museu de Arqueologia e Etnologia/ USP e SEMEC- Secretaria Municipal de Educação,Cultura e Desporto de Altamira. Cabendo à FUNCAMP administrar o projeto $\mathrm{e}$ gerenciar os recursos; o Instituto de Artes/ UNI-
CAMP e o MAE/USP forneceram o corpo técnico, cabendo também ao primeiro a ordenação de despesas do projeto; a Secretaria Municipal de Educação de Altamira recebeu os produtos do projeto (Cd Rom e curso) para sua divulgação na rede pública de ensino e utilização na escola indígena Asuriní. A FUNAI apoiou as ações articulando em campo a Secretaria Municipal de Educação e o Posto Indígena Koatinemo.

\section{Equipe USP / UNICAMP}

Regina Aparecida Polo Muller, Livre Docente em Antropologia da Dança/Docente do Programa de Pós-Graduação em Artes/UNICAMP e do Departamento de Artes Corporais- Instituto de Artes da UNICAMP. Responsável técnica pelo projeto.

Fabiola Andréa Silva, Doutora em Antropologia, pesquisadora e docente do MAE- Museu de Arqueologia e Etnologia da USP. Pesquisador do projeto.

Eduardo Néspoli, Doutorando pelo PGA- Programa de Pós-Graduação em Artes do Instituto de Artes da Unicamp. Pesquisador colaborador do projeto.

Alice Martins Villela Pinto, Mestranda pelo PGA- Programa de Pós-Graduação em Artes do Instituto de Artes da Unicamp. Pesquisadora e bolsista do projeto.

Rafael Franco Coelho, Mestrando pelo PGAPrograma de Pós Graduação em Artes do Instituto de Artes da Unicamp. Pesquisador, Designer e bolsista do projeto. 